\title{
Defect Probability Estimation for Hardness-Optimised Parts by Selective Laser Melting
}

\author{
Maurizio Galetto $^{1}$ (D) $\cdot$ Gianfranco Genta $^{1} \cdot$ Giacomo Maculotti $^{1} \cdot$ Elisa Verna ${ }^{1}$
}

Received: 24 February 2020 / Revised: 4 June 2020 / Accepted: 1 July 2020 / Published online: 20 July 2020

(c) The Author(s) 2020

\begin{abstract}
The development of reliable additive manufacturing (AM) technologies to process metallic materials, e.g. selective laser melting (SLM), has allowed their adoption for manufacturing final components. To date, ensuring part quality and process control for low-volume AM productions is still critical because traditional statistical techniques are often not suitable. To this aim, extensive research has been carried out on the optimisation of material properties of SLM parts to prevent defects and guarantee part quality. Amongst all material properties, defects in surface hardness are of particular concern as they may result in an inadequate tribological and wear resistance behaviour. Despite this general interest, a major void still concerns the quantification of their extent in terms of probability of defects occurring during the process, although it is optimised. Considering these issues, this paper proposes a novel approach to quantify the probability of occurrence of defects in hardness-optimised parts by SLM. First, three process variables, i.e. laser power, scan speed and hatching distance, are studied considering their effect on hardness. Design of Experiments and Response Surface Methodology are exploited to achieve hardness optimisation by controlling process variables. Then, hardness defect probability is estimated by composing the uncertainty affecting both process variables and their relationship with the hardness. The overall procedure is applied to $\mathrm{AlSi} 10 \mathrm{Mg}$ alloy, which is relevant for both aerospace and automotive applications. The approach this study proposes may be of assistance to inspection designers to effectively and efficiently set up quality inspections in early design phases of inspection planning.
\end{abstract}

Keywords Defect probability $\cdot$ Low-volume production $\cdot$ Parameter optimization $\cdot$ Selective laser melting $\cdot$ Hardness

\section{List of Symbols}

$X_{i} \quad$ Input variable $(i=1, \ldots, m)$

$Y_{j} \quad$ Output variable $(j=1, \ldots, n)$

$p_{Y_{j}} \quad$ Probability of occurrence of the defective-output variable $Y_{j}$

$U S L_{j} \quad$ Upper specification limit of output variable $Y_{j}$

$L S L_{j} \quad$ Lower specification limit of output variable $Y_{j}$

$E_{A} \quad$ Energy adsorption

$\psi \quad$ Energy density

HB Brinell hardness in the scale HBW 2.5/62.5

$h_{d} \quad$ In-skin hatching distance

$P \quad$ In-skin laser power

$t \quad$ Layer thickness

$v \quad$ In-skin scan speed

Maurizio Galetto

maurizio.galetto@polito.it

1 Department of Management and Production Engineering, Politecnico di Torino, Corso Duca degli Abruzzi 24, 10129 Turin, Italy

\section{Introduction}

Additive manufacturing (AM) is one of the most recent technologies that have been rapidly developing and integrating into manufacturing and our day-to-day lives. AM is defined in ISO/ASTM 52900:2015 as "the process of joining materials to make parts from 3D model data, usually layer upon layer, as opposed to subtractive manufacturing technologies and formative manufacturing methodologies" [1]. Synonyms found in the literature include additive processes, additive techniques, additive layer manufacturing, layered manufacturing, and solid freeform fabrication.

Parts produced by additive technologies are characterised by innovative shapes, complex features and lightweight structures, hard or even impossible to produce with conventional processes [2]. Parts production is carried out directly from computer-aided design (CAD) models without any sort of tools or fixtures and with negligible production of waste material [3, 4]. The development of AM technologies capable of processing metallic materials in the late 1990s 
played a transformational role regarding their application domains. In fact, AM parts, after years of being limited to producing polymeric visualization models and prototypes, are now used as end parts for several industrial sectors such as automotive, motor racing, medical, aerospace, defence [5, 6 ]. Therefore, ensuring the quality of additively produced parts is a fundamental need to meet the stringent requirements and certification constraints imposed by the sectors.

One of the most widespread metal AM process is selective laser melting (SLM) or direct metal laser sintering (DMLS) [7, 8]. In this process, a high-density object is built up layer by layer through the consolidation of metal powder particles with a focused laser beam that selectively scans the surface of the powder bed [3,9-13]. Metal powders, also reactive materials like titanium and aluminium, e.g. Ti6Al4V or AlSi10Mg alloys, are melted without the aid of a binder, as in the case for indirect laser sintering [14-18]. Recently, researchers have shown an increasing interest in the potential of this process that enables to build in one step full dense metallic parts with complex geometries which are used as final parts or functional prototypes $[4,19,20]$. Indeed, by choosing the proper input conditions, components by SLM can achieve equivalent or very similar mechanical properties to those of parts produced by traditional manufacturing techniques $[3,21]$. However, despite the versatility of the materials and shapes that can be achieved, SLM features some criticalities that require careful control of the process and the process variables used, which must be optimised to prevent defects from being generated.

Defects of metal components by SLM may be classified in the following categories: residual stresses; porosity; cracking and delamination; balling; geometric defects and dimensional accuracy; surface defects, and microstructural inhomogeneity and impurities [2]. The presence of such defects can severely affect the final quality and mechanical properties of SLM samples. However, due to the complex nature of the process and the differences between the properties of materials used, it is challenging to adopt standard methods to improve and optimise mechanical properties [22-24]. According to literature, controlling and changing properly the input variables may allow to obtain the desirable mechanical properties of the parts and conversely to limit the probability of defects generation. Specifically, the influence of the process variables on surface mechanical properties, and the subsequent identification of the values that optimise such properties, may be investigated through the use of experimental planning, e.g., factorial designs, and relevant statistical analysis using the analysis of variance (ANOVA) [25-28]. So far, despite the large amount of published studies focusing on the optimisation of the AM process, no specific attention has been paid to the remarkable issue of identifying the probability of defects generation occurring when the process is optimised. Indeed, even under optimal working conditions, namely when each process parameter is set at its optimal value, the probability of defects occurrence is never negligible because of the uncertainty affecting the overall manufacturing process. In this view, the objective of the study is to contribute to this growing area of research by proposing a methodology for the estimation of the probability of occurrence of defects related to a specific surface mechanical property, i.e. surface hardness. In particular, such probability is estimated for hardness-optimised AlSi10Mg samples produced by SLM process. First, the significance and the optimal values of process variables affecting hardness values are determined through statistically designed experiments. The Response Surface Methodology (RSM) is used to analyse the results [29]. Then, a mathematical model relating the significant process variables to the output response, i.e. hardness value, is developed and, as a result, optimised. Finally, the probability of the occurrence of hardness defect is estimated by exploiting and composing the uncertainty affecting both the obtained mathematical model and the input variables.

By applying methodologies already exploited in literature, this work moves forward to defining a method to estimate the probability of occurrence of defects, which still lacks in literature. This method represents a powerful tool for inspection designers to effectively and efficiently set up quality inspections of low-volume AM productions in early design phases of inspection planning [30, 31].

The rest of the paper is structured as follows: Sect. 2 presents the adopted defect prediction models, Sect. 3 describes the considered material and manufacturing process, Sect. 4 defines the analysis methodology, Sect. 5 details the experimental set-up, Sect. 6 discusses results, and Sect. 7 finally draws conclusions.

\section{Defect Prediction Model}

In order to evaluate the probability of occurrence of defects in the final part, the AM manufacturing process, in optimal working conditions, should be modelled as represented in Fig. 1. Specifically, $m$ process variables, also called input variables, may affect the final quality of the AM product. In order to evaluate product quality, $n$ output variables are measured on the AM part, using the most appropriate inspection method to detect the defect, e.g. dimensional verifications, mechanical tests, or visual checks [32-34]. In this situation, each input variable may potentially influence each output variable at different intensity levels. As represented in Fig. 1, each input variable is denoted as $X_{i},(i=1, \ldots, m)$ and each output variable is indicated as $Y_{j}(j=1, \ldots, n)$. Furthermore, for each output variable $Y_{j}$, a probability of occurrence of a defect, called $p_{Y_{j}}$, may be defined. It is worth 


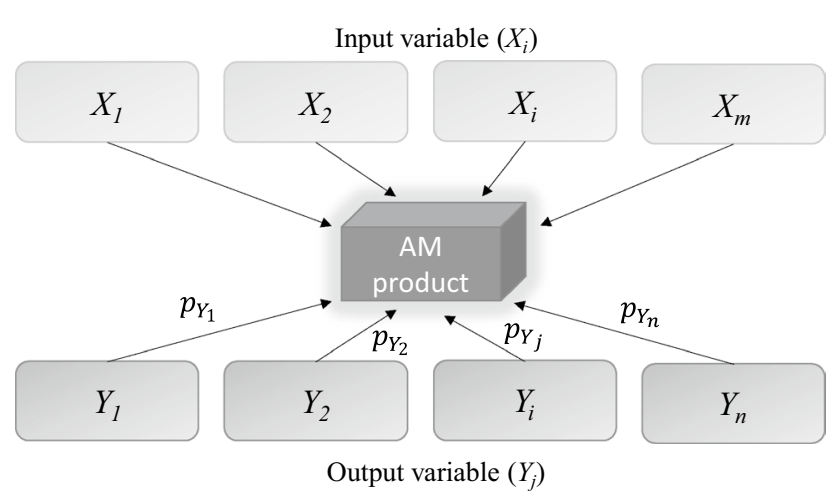

Fig. 1 Schematic of AM process with $m$ input variables and $n$ output variables measured on the AM product, with relative probabilities of occurrence of defects $\left(p_{Y_{j}}\right)$

remarking that the manufacturing process considered is in optimal working conditions, meaning that each input variable is set at its optimum value. Under such conditions, each $p_{Y_{j}}$ should be zero; however, in realistic cases, this almost never happens because of uncertainty. Consequently, it is of the utmost importance to estimate such probabilities of occurrence of defects in order to effectively and efficiently plan quality inspections on the final product [35].

The probabilities of occurrence of defects, $p_{Y_{j}}$, are closely related to the intrinsic characteristics of the process. Accordingly, they can be evaluated by using empirical methods, e.g. historical data, previous experience on similar processes, knowledge of the process, or by implementing probabilistic models [36-38]. In the case of AM productions, which are small-sized lots or even unique parts, the historical data are often not available, requiring the formulation of a probabilistic model that exploits the knowledge of the production process.

The model developed in this work relies on the assumption that a relationship between input and output variables exists. Consequently, if the adopted inspection procedure detects a defect related to the output variable, this can be caused by some input variables or by their interaction. The probabilities of occurrence of defective-output variables can, therefore, be obtained based on the mathematical function that relates input variables with output variables [39]. Moreover, the proposed methodology requires the knowledge of the values of input variables that result in the best values of output variables. Thus, the AM process must be optimised, and the input variables must be set to their optimal value. Finally, the specification limits of the output variables (upper specification limit, $U S L_{j}$, and lower specification limit, $L S L_{j}$ ) are necessary to determine whether the products meet the specifications imposed by company regulations and/or standards. Input variables can be discrete or continuous variables. Since most of the process variables set on AM machines are continuous variables, only these are covered in detail in this study.

The methodology adopted to estimate the probability of occurrence of defective-output variables relies on the composition of the uncertainty coming from the mathematical function that relates the input and output variables, and from the uncertainty deriving from maintaining the input variables at their optimal value [35]. Specifically, since in practical applications, the mathematical function is not exactly defined, it implies that its coefficients are affected by uncertainty. Also, the optimal values of the input variables are often not exact because of the uncertainty of the measurement device. Accordingly, a variability range must be associated with them. The probability distribution associated with input variables depends on their characteristics, e.g. a uniform distribution should be considered, if the values are all equiprobable in the interval. The variance of the probability distribution of each output variable may, therefore, be estimated by composing the uncertainties associated to both the input variables and the mathematical function, through the law of composition of variances for linear or linearizable model [40]. In formulas, defined the vector of the $m$ input variables as $\boldsymbol{X}=\left[x_{1}, \ldots, x_{m}\right]^{\mathrm{T}}$, the uncertainty of each input variable contributes to the variance of the related $Y_{j}$ output variable, together with the contribution of the mathematical function coefficients, $\boldsymbol{A}=\left[a_{0}, a_{1}, \ldots, a_{m}\right]^{\mathrm{T}}$, as shown in Eq. (1) [35]:

$\operatorname{VAR}\left(Y_{\mathrm{j}}\right) \approx\left[\frac{\partial Y_{\mathrm{j}}}{\partial \boldsymbol{K}}\right]^{\mathrm{T}} \cdot \operatorname{cov}(\boldsymbol{K}) \cdot\left[\frac{\partial Y_{\mathrm{j}}}{\partial \boldsymbol{K}}\right] \quad(j=1, \ldots, n)$

where $\boldsymbol{K}$ is the vector of size $2 m+1$ of the input variables and the coefficients of the mathematical function, defined as $\boldsymbol{K}=[\boldsymbol{X}, \boldsymbol{A}]^{\mathrm{T}}, \operatorname{cov}(\boldsymbol{K})$ is the variance-covariance matrix [41] and $\left[\frac{\partial Y_{j}}{\partial K}\right]$ is the vector of the partial derivatives of $Y_{j}$ with respect to each component of $\boldsymbol{K}$.

Since the distribution of each output variable $Y_{j}$ originates by many different random contributions, it can be approximated to a normal distribution according to the central limit theorem [42]. Thus, each probability $p_{Y_{j}}$, which represents the probability that $Y_{j}$ falls outside the specification limits $\left(L S L_{j}\right.$ and $\left.U S L_{j}\right)$, can be estimated by computing the area of the normal distribution outside the two specification limits, according to Eq. (2):

$p_{Y_{j}}=1-P\left(L S L_{j} \leq Y_{j} \leq U S L_{j}\right)$ 


\section{Material and Process}

This section describes the material and the additive manufacturing process considered in the present work, with highlights on their industrial application and focusing on the process variables known to influence material properties.

\subsection{AlSi10Mg Alloy}

Aluminum-Silicon alloys are extremely attractive cast aluminum alloys thanks to their high fluidity, weldability, corrosion resistance and low coefficient of thermal expansion. Moreover, the presence of magnesium as alloying element promotes the formation of precipitates of $\mathrm{Mg}_{2} \mathrm{Si}$. These strengthen the matrix and enable effective hardening to be achieved through heat treatments or rapid solidification techniques, but limit the feasible design [11, 19, 23, 43-45]. Therefore, aluminum alloys are of great interest for automotive and aerospace industries due to their combination of high strengths, low densities and thermal capacity [44], finding application in heat exchangers, heat sinks, turbine blades, carters and cylinder blocks [46, 47]. Furthermore, near-eutectic composition, thanks to the small solidification range, ease their processing by laser [43]. Therefore, AlSi10Mg is an alloy which is particularly suitable and interesting for SLM processing, which, ultimately, enables freedom design for this high-performance material.

\subsection{Selective Laser Melting}

SLM was born, as patent deposition, in 1987 and has been developed since the early 2000s, mostly from the point of view of the capability of processing mono-component material, which eventually enabled for production application.

The part building process takes place inside an enclosed chamber filled with nitrogen gas to minimise oxidation and degradation of the powdered material, or inert gas, e.g. Argon or Helium, to avoid material to react with the environment.

An infra-red heater maintains the powder in the build platform at an elevated temperature, just below its the melting point or its glass transition temperature, to reduce the laser power needed to locally melt the powder and the heat exchange which is a source of warping. As soon as a counter-rotating roller spreads a layer of powder on the building platform, which must be ground and polished, a focused laser beam is directed onto the powder bed and is moved using galvanometers. In such a way, the laser beam thermally fuses the material to form the slice cross-section. Surrounding powder remains loose and serves as support for subsequent layers, thus eliminating the need for the secondary supports which are necessary for photopolymer vat processes. After completing a layer, the build platform is lowered by one-layer thickness, $t$, typically $(20-50) \mu \mathrm{m}$ for metal, and a new layer of powder is laid, and the beam scans the subsequent cross-section. Schematic of the process system's main component is shown in Fig. 2 [48].

In the present work, the EOS M 290 SLM machine is considered. This platform is a high productivity system of limited dimensions that enables to build components within a volume of $(250 \times 250 \times 320) \mathrm{mm}$. It features a Yb-fibre laser with a nominal power of $400 \mathrm{~W}$ and a focus diameter of $100 \mu \mathrm{m}$, with a scanning control based on $f$ - lenses with a focal length of $410 \mathrm{~mm}$, that operates in an Argon shielded environment.

In order to achieve total quality management, the whole influencing factors in the AM process chain must be catered for $[49,50]$, as shown in Fig. 3. Through the SLM process, five aspects have the most significant impact, these being Equipment, Material, Production, Batch and Part. However, only few can be actually controlled and, moreover, a thorough understanding of their effect on the process is far from being achieved.

Literature $[3,23,51-53]$ provides an overview of most relevant influencing factors along with systematic study, by means of ANOVA, DoE and RSM, of their effect on material characterisation, both from mechanical and topographical perspectives. Amongst those, process variables represent a subset the component manufacturer can act on to achieve control and optimisation of the process. According to Gibson et al. [48], notwithstanding their effects are intertwined, process variables can be divided into four categories: (1) laser-related variables (e.g. laser power, spot size), (2) scan-related variables (scan speed, scan spacing or hatching distance, and scan pattern), (3) powder-related variables (e.g. particle shape, size and distribution, powder

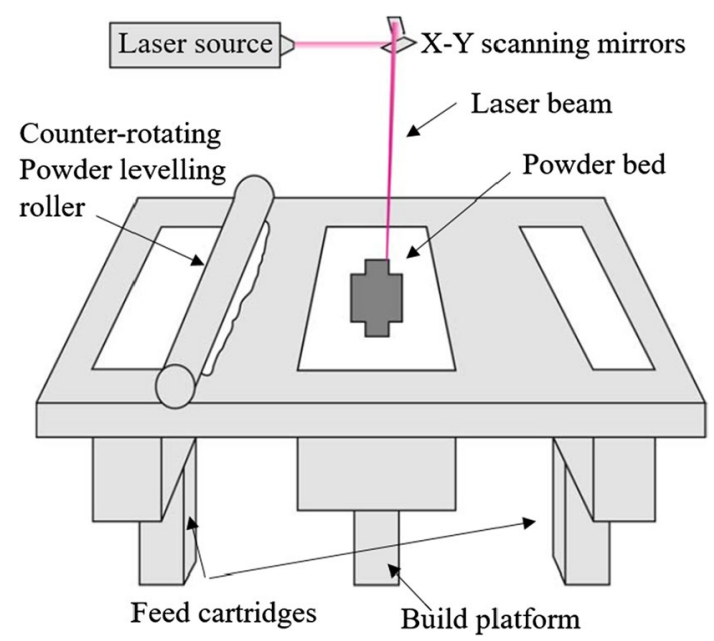

Fig. 2 Schematic of SLM. Adapted from Gibson et al. [48] 


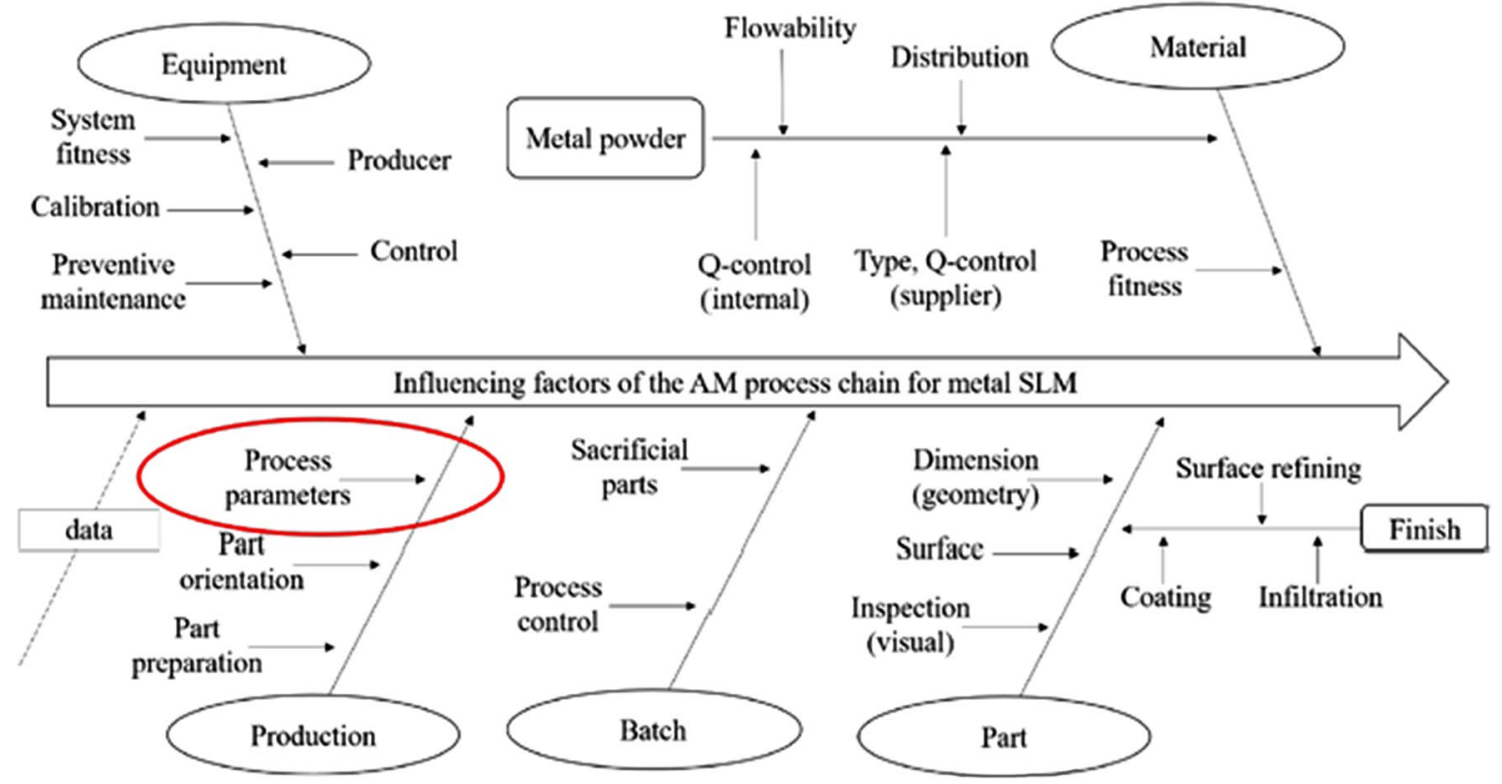

Fig. 3 Ishikawa diagram: influencing factors within AM process chain for SLM. Adapted from Schmidt et al. [19]

\begin{tabular}{|c|c|c|c|c|c|c|}
\hline \multicolumn{4}{|c|}{2} & \multirow[b]{3}{*}{2} & & \\
\hline 1 & 4 & 3 & & & & \\
\hline & & 3 & 4 & & & \\
\hline & & 3 & & 4 & 2 & \\
\hline & & 3 & & & 4 & 2 \\
\hline & & 1 & & & & \\
\hline
\end{tabular}

Legend

1: down-skin

2: up-skin

3: in-skin

4: overlapping

Fig. 4 Up-skin, down-skin and core regions Adapted from Manfredi et al. [59]

bed density, layer thickness, material properties), and (4) temperature-related variables (e.g. powder bed temperature, powder feeder temperature, temperature uniformity) $[43,54]$.

Along the building direction, different boundary conditions for heat exchange between the layer and the environment are met during the build. In fact, the bottom region is in contact with the building platform, below it, and laser exposed areas, above it; the top region has exposed areas below and the region in between them contacts exposed areas above and below itself [55-57]. These three regions can be respectively named as the down-skin, the up-skin and the core or in-skin $[3,11,48,58-60]$, as shown in Fig. 4. In order to optimise the process, it is standard practice to set up different process parameter for each of these three regions, considering that the down-skin consists of two layers and the up-skin of three [11, 58]. Literature [3, 11, 43, 60, 61] has shown that this region-wise differentiated parameter set-up can both relieve the effect of boundary condition for heat exchange and achieve control of material properties. In fact, according to Fig. 4, up- and down-skin variables are related to surface properties, whilst in-skin variables to the core, bulk average properties of the component.

\subsection{Influence of Process Variables on Material Defects}

Due to its application field, see Sect. 3.1, previous research has investigated the effect of main process variables on mechanical properties of SLM parts, mostly for AlSi10Mg alloy. For example, Manfredi et al. reported that the DMLS-fabricated AlSi10Mg alloy exhibited significantly higher yield stress compared to its as-cast counterpart [11]. Krishnan et al. found that among the process variables, hatch spacing had the most significant effect on the part mechanical properties, being capable of controlling the surface finish and the surface hardness, hence the wear and tribological behaviour of the component [58]. In another study, Yan et al. investigated the effect of volume fraction on the compressive strength and hardness of the DMLS-fabricated lattice structures [62]. They also achieved near fully dense struts of AlSi10Mg lattice structures due to the overlap of melt pools. Ghasri-Khouzani et al. tried to distinguish the difference in microstructure and mechanical properties of different AM part planes [44]. Kempen et al. showed that AlSi10Mg parts produced by SLM have mechanical properties higher or at least comparable to the cast material because of the very fine microstructure [63], promoted by the layer remelting. A large amount of studies in literature reveals that controlling and properly changing the input variables allows obtaining the desirable mechanical properties of the parts and conversely to limit the probability of defects generation. 
In particular, the present paper focuses on the effect of laser power, $P$, the hatching distance, $h_{d}$, and the scan speed, $v$, of the in-skin.

Due to its working principle, SLM can be compared for issues (warping, thermal gradient, residual stresses) to casting, even though with quite the opposite microstructural remelts and definitively without casting design constraints [64]. Laser source must be capable of generating a laser with a power sufficient to melt the layer and part of the layer underneath, in order to guarantee adequate adhesion: the greater the laser power, the larger the remelt zone. Because of the cyclic melting of layers, a fine microstructure results which sometimes requires devoted heat treatments to be performed. Moreover, since the laser power controls the severity of the temperature gradient, it has, therefore, a significant effect on the surface properties. Indeed, thermal gradient and resulting shrinkage may generate residual stresses leading to an increase of the probability of warping and cracks onset, which, though, can be relieved by slight oversizing the part $[65,66]$ and by devoted scanning strategies. The laser locally melts the cross-section with a pattern, i.e. scanning strategy, aimed at minimising the thermal gradient and the residual stresses in the component, e.g. by means of the offset island strategy [50,60]; laser scans at a certain speed, $v$, which is critical to be appropriately set as it determines the amount of energy introduced during melting, hence influencing material properties and structure. Indeed, as described by Childs et al. [67], excessively high speed may hinder from melting to occur or yields to balling whereas low speed entails high energy adsorption, $E_{A}$, defined according to Eq. (3):

$E_{A}=\frac{P}{h_{d} \cdot v}\left[\frac{\mathrm{J}}{\mathrm{mm}^{2}}\right]$

Furthermore, complex interactions between $P, v$ and scanning strategy increase the complexity of the setup of this parameter [67]. To fill the cross-section, laser scans lines according to the scanning strategy and the distance between the centre of two adjacent lines is the hatching distance or scan spacing, $h_{d}$, which is, therefore, a measure of the overlap of lines. In particular, multiple overlapping lines entails several passes of the laser on the same point, thus enabling higher $v$ to be adopted $[48,67]$. Moreover, if the distance between two adjacent scan lines is larger than the diameter of the laser beam, the metal powders do not bind together well. Consequently, high hatch density entails greater energy adsorption and yields to higher mechanical strength [3], hardness and, in general, improved tribological behaviour, thus decreasing the probability of defects generation.

Adhesion between layers is core to be achieved to avoid delamination and high part density and hardness. In particular, devoted scanning strategies have been developed to improve bonding of the layers, e.g. the alternate $x y$ and the rotated hatch pattern [50, 59]. Furthermore, layer thickness $t$ has been demonstrated to affect adhesion, depending on energy absorption [50].

Therefore, considering the variables accounted by the present work, the laser heat input is using the energy density function, $\psi$, which is described by Eq. (4):

$\psi=\frac{P}{h_{d} \cdot v \cdot t}\left[\frac{\mathrm{J}}{\mathrm{mm}^{3}}\right]$

More in general, the laser heat input is strictly related to the degree of consolidation of the powder particles, and it may increase the probability of defects generation, if not appropriately set, by creating turbulence in the melt pool that can form a keyhole-like defect in the extreme conditions [50]. Consequently, it is often adopted in literature as a reference parameter for the setup of ANOVA, DoE and RSM analysis of influencing factors on material properties [43].

Amongst the several mechanical properties, this work focuses on the hardness. This measurement evaluates a characteristic that allows inferring other properties of the material, e.g. plasticity. However, as far as the influence of process variables is concerned, here is relevant to recall the works of $\mathrm{Li}$ and $\mathrm{Gu}$ [68], Song et al. [69], Lam et al. [70], Li et al. [71] and Ghasri-Khouzani et al. [44]. They demonstrated that the local melting and high cooling rate typical of SLM process yield to a finer microstructure. Thus, materials by SLM are characterised by greater hardness, and hence higher strength, with respect to cast or wrought parts. These properties are further enhanced by the alloying elements and the interactions of dislocation for the AlSi10Mg. SLM introduces anisotropy in the material due to the layer-by-layer building strategy; however, it has been demonstrated that at least at macro and micro scales it does not introduces significant differences in the material mechanical behaviour [44].

\section{Analysis Methodology}

This section presents the methodologies adopted for arranging the tests and analysing experimental data to optimise the SLM process. Design of Experiment (DoE) is an effective statistical approach for optimising the process when a combination of different input variables and their interactions affect selected responses [72]. Then, Response Surface Methodology (RSM) uses experimental designs to fit the model by the least-squares technique. In fact, RSM is a collection of mathematical and statistical techniques aimed for the empirical exploration of the relationship between continuous response(s) and a set of input factors [29]. In the exploratory stages of model building, stepwise regression may be used to identify the best subset of predictors. It is an automatic technique implemented in several statistical 
software such as MINITAB ${ }^{\circledR}$, which is used in this analysis. Stepwise regression both adds and removes predictors at each step, according to selected Alpha-to-Enter and Alphato-Remove values [29]. The Analysis Of Variance (ANOVA) is used to estimate the statistical significance of variables' effects with respect to the observed differences in response. Diagnostic checking test, e.g. coefficients of determination and residuals plots, are exploited to verify the underlying assumptions to perform the ANOVA and ultimately demonstrate the model adequacy. Finally, the response surface plots can be employed to study the surfaces and locate the optimum. For this reason, the RSM is usually used to assess results and efficiency of operations [50].

\section{Experimental Setup}

As mentioned in Sect. 3.3, and according to literature, in this case study, the input variables were laser power, scan speed and hatching distance of the in-skin. The three input, i.e. $P$, $v$ and $h_{d}$, if not adequately set, may determine the generation of several defects, e.g. warpage, cracking, unsatisfactory powder bonding and microstructure dimension. Hence, their set-up controls the quality outputs of the parts. The output variable measured on the samples was surface hardness. Samples geometry (see Fig. 5) was designed to perform, in forthcoming analyses, measurements of surface roughness, in addition to the hardness tests.

In order to obtain optimal process variables that result in the best values of hardness, an experimental plan was designed. Specifically, a $3^{3}$ full factorial design was realised in order to investigate possible quadratic effects of input variables. The three input variables related to the in-skin, laser power $(P)$, scan speed $(v)$ and hatching distance $\left(h_{d}\right)$, were kept at three levels (see Table 1). For each of the 27 parts, the contour of the layer structure was exposed with the same value of speed $(1000 \mathrm{~mm} / \mathrm{s})$ and laser power $(355 \mathrm{~W})$ of the up-skin. In addition, a strategy of post-contour was realised (with a speed of $900 \mathrm{~mm} / \mathrm{s}$ and a power of $80 \mathrm{~W}$ ).

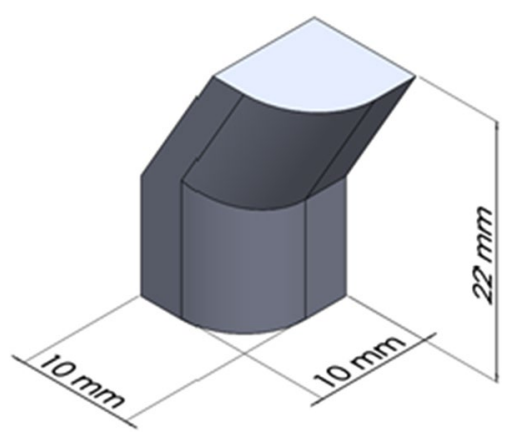

Fig. 5 Samples geometry
Table 1 Process variables values used in the planned experimentation

\begin{tabular}{ll}
\hline Process variable & Values \\
\hline$P(\mathrm{~W})$ & $340-355-370$ \\
$v(\mathrm{~mm} / \mathrm{s})$ & $900-1300-1700$ \\
$h_{d}(\mathrm{~mm})$ & $0.11-0.15-0.19$ \\
\hline
\end{tabular}

The choice of the levels of the process variables set in the experimental plan allowed to get a wide range of energy density function, $\psi$, see Eq. (4). Specifically, $\psi$ varied from 35.09 to $124.58 \mathrm{~J} / \mathrm{mm}^{3}$, as it will be shown in Sect. 6.1 . The experiments were not randomised because of the high repeatability of the machine allowed building the samples in a single job, by varying process variables for each sample. This approach, as a first approximation, is the one adopted in the computer experiment field.

After the production, the 27 specimens for hardness measurements were polished, see Fig. 6a. Then, the Brinell hardness test was performed according to the industrial standard ISO 6506-1:2014 [73]. The test was carried out using a sphere with a diameter of $2.5 \mathrm{~mm}$ and applying a force of $62.5 \mathrm{kgf}$, thus evaluating Brinell hardness in the scale HBW 2.5/62.5 to provide a reference to powder supplier specification. The average value of three measurements for each sample was examined, to cater for the measurement procedure variability. Figure $6 \mathrm{~b}$ shows the Brinell hardness test performed on the specimens.

\section{Results and Discussion}

After collecting the data obtained from the Brinell hardness measurements on the 27 samples of the experimental plan, the statistical analysis was performed, using the

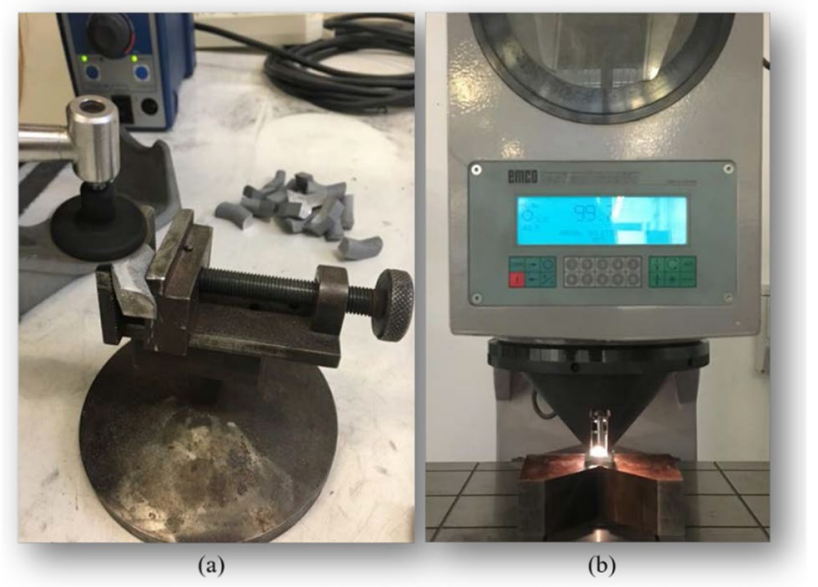

Fig. 6 a Samples polishing and $\mathbf{b}$ samples Brinell hardness test 
RSM. The average of the three hardness measurements carried out on the samples was examined, as shown in Table 2.

\subsection{ANOVA Results}

The arrangement of the full factorial design, as shown in Table 2, allowed the identification of the appropriate empirical equation, i.e. a second-order polynomial multiple regression equation. The standard stepwise regression was adopted to obtain a model containing exclusively significant factors. The values of Alpha-to-Enter and Alpha-to-Remove were set to $10 \%$ to allow entering terms close to the significance level of 5\%. The software MINITAB ${ }^{\circledR} 17.1$ was used to perform the analysis. The RSM provided the analysis of variance (ANOVA) (see Table 3), the coefficients of the regression models with

Table 2 Arrangement of the experimental design for the three independent variables, together with corresponding energy densities and experimental values of Brinell hardness

\begin{tabular}{|c|c|c|c|c|c|}
\hline Run & $P(\mathrm{~W})$ & $V(\mathrm{~mm} / \mathrm{s})$ & $h_{d}(\mathrm{~mm})$ & $\psi\left(\mathrm{J} / \mathrm{mm}^{3}\right)$ & $\begin{array}{l}\text { Hardness } \\
H B(\mathrm{HB})\end{array}$ \\
\hline 1 & 340 & 900 & 0.11 & 114.48 & 85.7 \\
\hline 2 & 340 & 900 & 0.15 & 83.95 & 90.3 \\
\hline 3 & 340 & 900 & 0.19 & 66.28 & 103.7 \\
\hline 4 & 340 & 1300 & 0.11 & 79.25 & 96.7 \\
\hline 5 & 340 & 1300 & 0.15 & 58.12 & 115.0 \\
\hline 6 & 340 & 1300 & 0.19 & 45.88 & 121.0 \\
\hline 7 & 340 & 1700 & 0.11 & 60.61 & 120.3 \\
\hline 8 & 340 & 1700 & 0.15 & 44.44 & 118.7 \\
\hline 9 & 340 & 1700 & 0.19 & 35.09 & 119.7 \\
\hline 10 & 355 & 900 & 0.11 & 119.53 & 76.0 \\
\hline 11 & 355 & 900 & 0.15 & 87.65 & 87.7 \\
\hline 12 & 355 & 900 & 0.19 & 69.20 & 99.7 \\
\hline 13 & 355 & 1300 & 0.11 & 82.75 & 108.0 \\
\hline 14 & 355 & 1300 & 0.15 & 60.68 & 116.3 \\
\hline 15 & 355 & 1300 & 0.19 & 47.91 & 119.7 \\
\hline 16 & 355 & 1700 & 0.11 & 63.28 & 114.7 \\
\hline 17 & 355 & 1700 & 0.15 & 46.41 & 118.7 \\
\hline 18 & 355 & 1700 & 0.19 & 36.64 & 115.3 \\
\hline 19 & 370 & 900 & 0.11 & 124.58 & 78.7 \\
\hline 20 & 370 & 900 & 0.15 & 91.36 & 87.3 \\
\hline 21 & 370 & 900 & 0.19 & 72.12 & 84.7 \\
\hline 22 & 370 & 1300 & 0.11 & 86.25 & 100.3 \\
\hline 23 & 370 & 1300 & 0.15 & 63.25 & 110.3 \\
\hline 24 & 370 & 1300 & 0.19 & 49.93 & 118.3 \\
\hline 25 & 370 & 1700 & 0.11 & 65.95 & 120.3 \\
\hline 26 & 370 & 1700 & 0.15 & 48.37 & 116.3 \\
\hline 27 & 370 & 1700 & 0.19 & 38.18 & 116.3 \\
\hline
\end{tabular}

Table 3 ANOVA for hardness $H B$ (HB)

\begin{tabular}{lrcrc}
\hline Source & $d f$ & Sum of squares & \multicolumn{1}{c}{$F$} & $p$-value $(\%)$ \\
\hline$P$ & 1 & 81.64 & 3.93 & 6.1 \\
$v$ & 1 & 3950.62 & 190.29 & $<0.1$ \\
$h_{d}$ & 1 & 529.93 & 25.53 & $<0.1$ \\
$v \cdot v$ & 1 & 458.40 & 22.08 & $<0.1$ \\
$v \cdot h_{d}$ & 1 & 222.45 & 10.72 & 0.4 \\
Residual error & 21 & 435.98 & & \\
Total & 26 & 5679.02 & & \\
\hline
\end{tabular}

their standard errors (see Table 4), and the regression equation shown in Eq. (5).

$H B=\beta_{0}+\beta_{1} \cdot P+\beta_{2} \cdot v+\beta_{3} \cdot h_{d}+\beta_{4} \cdot v^{2}+\beta_{5} \cdot v \cdot h_{d}$

The predicted response, i.e. the Brinell hardness $H B$, was therefore related to the set of regression coefficients $(\beta)$ : the intercept $\left(\beta_{0}\right)$, linear $\left(\beta_{1}, \beta_{2}, \beta_{3}\right)$, interaction $\left(\beta_{5}\right)$ and quadratic coefficient $\left(\beta_{4}\right)$. As mentioned in Sect. 5 , in this analysis, Brinell hardness is evaluated in the scale HBW 2.5/62.5; however, for simplicity of notation, the corresponding measurement unit is only indicated by the symbol HB.

By performing a qualitative analysis on the main effect of the process variables and observing the main effect plot, shown in Fig. 7, it can be concluded that all three input variables have a main effect on hardness. In the main effect plot, the higher the slope of the line which connects the levels of the process variables, the greater the influence of each variable is. The main effect on the hardness seems to be due to the scan speed $v$ : a speed of $900 \mathrm{~mm} / \mathrm{s}$ produces a hardness of about $90 \mathrm{HB}$; conversely, using a speed of $1700 \mathrm{~mm} / \mathrm{s}$ the resulting hardness is about $120 \mathrm{HB}$. The second variable, which has the greatest effect on hardness, is the hatching distance $h_{d}$, whilst the laser power $P$ seems to have a weaker effect than the other process variables. It is worth noting that the trends are of direct proportionality for the scan speed and the hatching distance and inverse proportionality for the laser power: lower laser power yields

Table 4 Estimates of parameters of the regression model (see Eq. 5) and their standard errors

\begin{tabular}{llll}
\hline Variable & Parameter & Estimate of parameter & $\begin{array}{l}\text { SE on } \\
\text { estimate of } \\
\text { parameter }\end{array}$ \\
\hline constant & $\beta_{0}(\mathrm{HB})$ & $-5.12 \times 10^{1}$ & $3.57 \times 10^{1}$ \\
$P$ & $\beta_{1}(\mathrm{HB} / \mathrm{W})$ & $-1.42 \times 10^{-1}$ & $7.16 \times 10^{-2}$ \\
$v$ & $\beta_{2}(\mathrm{HB} /(\mathrm{mm} / \mathrm{s}))$ & $2.19 \times 10^{-1}$ & $3.28 \times 10^{-2}$ \\
$h_{d}$ & $\beta_{3}(\mathrm{HB} / \mathrm{mm})$ & $4.85 \times 10^{2}$ & $1.10 \times 10^{2}$ \\
$v \cdot v$ & $\beta_{4}\left(\mathrm{HB} /(\mathrm{mm} / \mathrm{s})^{2}\right)$ & $-5.46 \times 10^{-5}$ & $1.16 \times 10^{-5}$ \\
$v \cdot h_{d}$ & $\beta_{5}\left(\mathrm{HB} /\left(\mathrm{mm}^{2} / \mathrm{s}\right)\right)$ & $-2.69 \times 10^{-1}$ & $8.22 \times 10^{-2}$ \\
\hline
\end{tabular}



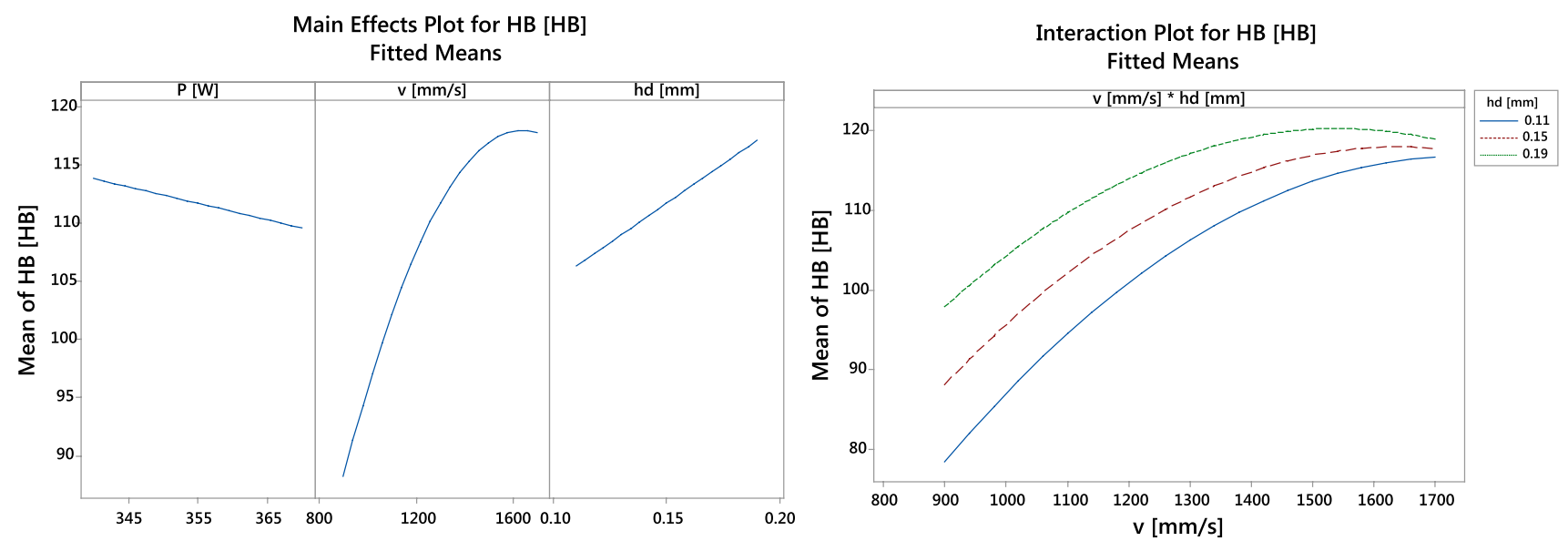

Fig. 7 Main effects plot and interaction plot for hardness $H B(\mathrm{HB})$

better, i.e. greater, hardness. On the contrary, diminishing the scanning speed and the hatching distance, worse values of hardness are obtained. The analysis of variance confirms these results (see Table 3). Indeed, it emerges that $v$ and $h_{d}$ are highly significant, i.e. their $p$-values are less than $0.1 \%$, and $P$ is significant at a $6 \%$ significance level.

With respect to the quadratic terms in Table 3, only the effect of the scan speed is found to be highly significant. The interactions between variables can be visualised with the interaction plot, shown in Fig. 7. Parallel lines in an interactions plot indicate no interaction. The greater the departure of the lines from the parallel state, the higher the degree of interaction. The graph shows that it is possible to obtain high $H B$ using high values of scan speed and high values of hatching distance and, there are strong interactions between these two variables. The ANOVA confirms that result, by showing that the interaction between $v$ and $h_{d}$ is highly significant $(p$ value of $0.4 \%$ ). Furthermore, the RSM provided the estimates of the regression model's parameters, see Eq. (5), with their standard errors, which are reported in Table 4. The analysis of residuals, i.e. the differences between the observed and the corresponding fitted values, is shown in Fig. 8 and suggests that the model fits the data well. The normality of the residuals is confirmed graphically both by the normal probability plot (NPP), in which the points follow approximately a straight line, and by the histogram (see Fig. 8). Furthermore, by performing the Anderson-Darling test, the null hypothesis that the residuals follow a normal distribution cannot be rejected at a significance level of 5\% [41]. The plot of residuals versus fitted values shows a horizontal band around the residual line (value 0 ) and no recognizable patterns are found. However, the residuals versus
Fig. 8 Residual plots for hardness $H B(\mathrm{HB})$

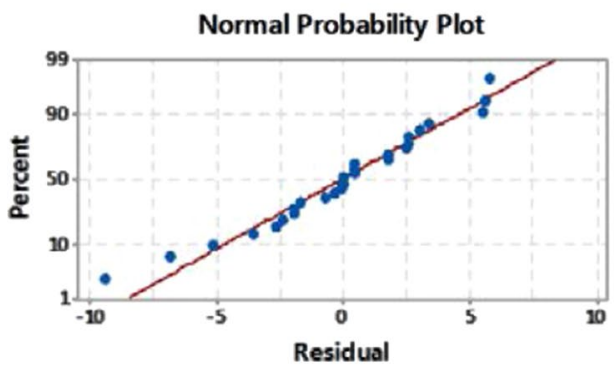

Residual Plots for hardness HB [HB]
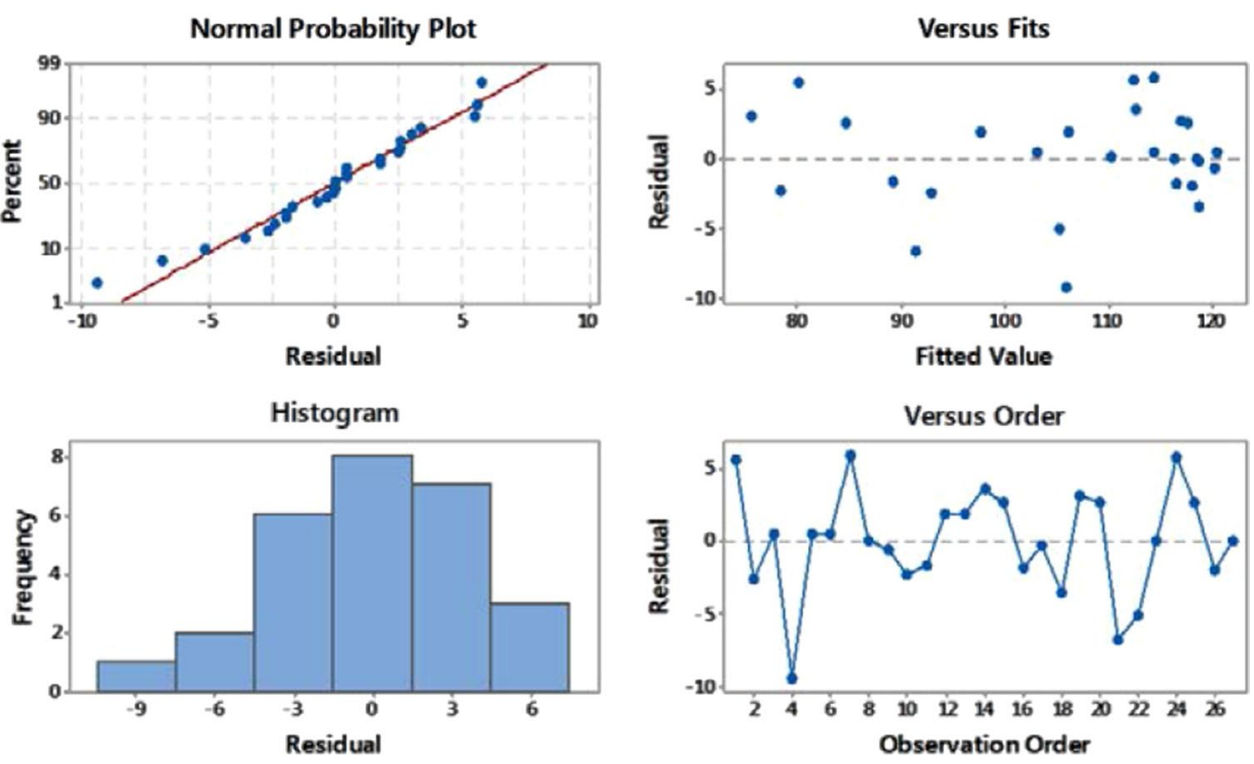
order plot reveals that non-random error, especially of timerelated effects, may be present. The $R^{2}$ value is a measure of goodness of fit of the model. It shows that the variation in the response explained by the model describing the relationship between the process variables and the Brinell hardness is $92.3 \%$. Even the predicted $R^{2}$ value is very high, reaching $85.9 \%$, suggesting a great predictive capability of the model.

In Fig. 9, surface plots showing how the fitted response relates to the three pairs of independent variables are reported. A surface plot displays the three-dimensional relationship with the independent variables on the $x$ - and $y$-axis, and the response $(z)$ variable represented by a smooth surface. The graphs are generated by calculating fitted responses using the independent variables while holding the third control variable constant at the central value.

\subsection{Process Optimisation}

In order to find the values of laser power, scan speed and hatching distance of the in-skin resulting in the best value of hardness, a response optimisation was performed. Specifically,
Table 5 Process setup (maximum $H B$ )

\begin{tabular}{|c|c|c|c|c|c|}
\hline \multicolumn{4}{|c|}{ Control factors } & \multicolumn{2}{|c|}{ Response predicted value } \\
\hline$P(\mathrm{~W})$ & $v(\mathrm{~mm} / \mathrm{s})$ & $h_{d}(\mathrm{~mm})$ & $\psi\left(\mathrm{J} / \mathrm{mm}^{3}\right)$ & $\begin{array}{l}\text { Response } \\
\text { value } \\
\text { (HB) }\end{array}$ & $\begin{array}{l}\text { Response } 95 \% \\
\text { CI (HB) }\end{array}$ \\
\hline 340 & 1538.4 & 0.19 & 38.78 & 122.45 & $(118.08 ; 126.83)$ \\
\hline
\end{tabular}

Response optimisation and predicted value

the objective function was set to maximise the hardness. Process variables setups and the respective value of energy density $\psi$, are summarised in Table 5, together with the predicted value of hardness and the related 95\% confidence interval. In Fig. 10, the optimisation plot for $H B$ is reported. Such a plot shows the effect of each factor on the response. The factors are reported in the columns and the response in the row. The vertical red lines on the graph represent the optimal factor settings, whose values are displayed in red at the top of each column. The horizontal blue line and value represent the response for the optimal factor levels. As far as $P$ and $h_{d}$ values are concerned, they
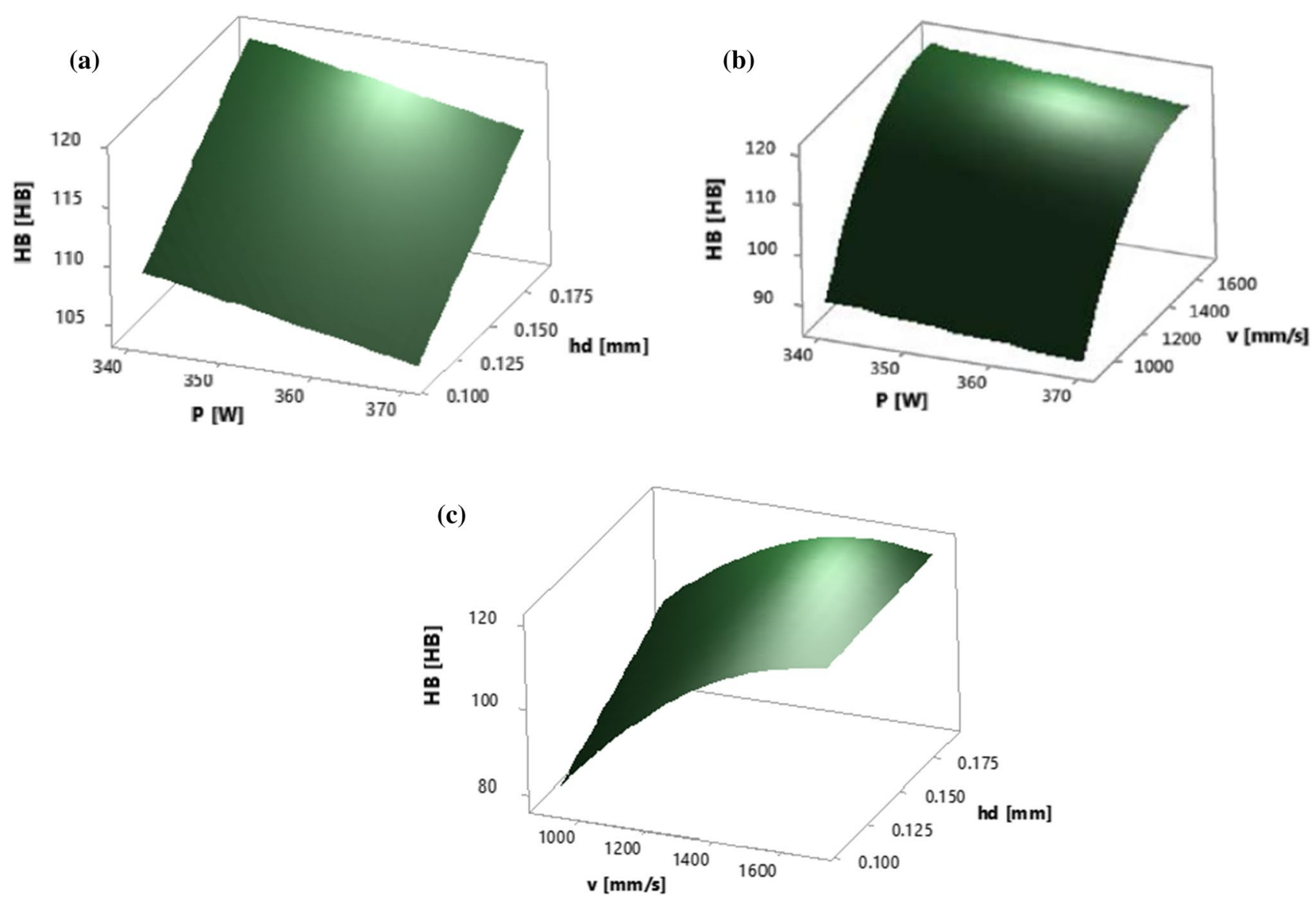

Fig. 9 Surface plot of hardness $H B$ (HB) versus: a hatching distance $h_{d}(\mathrm{~mm})$ and laser power $P(\mathrm{~W})$ (scan speed $v$ was set to $1300 \mathrm{~mm} / \mathrm{s}$ ); b scan speed $v(\mathrm{~mm} / \mathrm{s})$ and laser power $P(\mathrm{~W})$ (hatching distance $h_{d}$ was set to $0.15 \mathrm{~mm})$; c versus hatching distance $h_{d}(\mathrm{~mm})$ and scan speed $v(\mathrm{~mm} / \mathrm{s})$ (laser power $P$ was set to $355 \mathrm{~W})$ 
Fig. 10 Optimisation plot for hardness $H B(\mathrm{HB})$

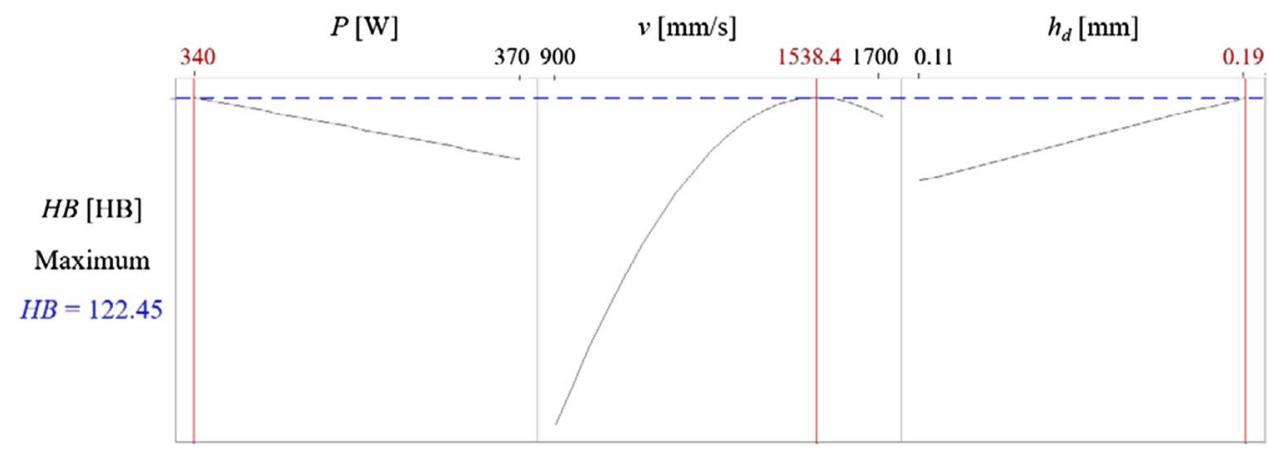

are situated at the limits of the ranges selected for the planned experimentation. Specifically, $P$ is located at the lower limit of the range and $h_{d}$ at the upper limit. Regarding $v$, the value that leads to the optimal hardness is placed at about three-quarters of the interval. This parameter set corresponds to a low energy density value $\left(38.78 \mathrm{~J} / \mathrm{mm}^{3}\right)$ if compared to those obtained in the planned experimentation (see Table 2).

From a physical point of view, the obtained values can be considered reasonable. In fact, when the energy density is too high, i.e., increasing laser power and decreasing scan speed, the melt pool volume increases, and its viscosity decreases, leading to irregularities and a very deep penetration into the previously formed layers, and partial evaporation takes place [63]. Conversely, when the energy density is too low, a partial penetration of the melt pool to the underlying layers occurs, wetting is unsatisfactory and droplets are formed [3, 63]. The obtained process variables setup, which lies in the process window defined by Kempen et al. [63], allows getting parts characterised by good mechanical properties, in this case high hardness.

\subsection{Estimation of Probability of Occurrence of Hardness Defect}

According to Eq. (1), the variance of the output variable $\mathrm{HB}$ was obtained by composing the uncertainty of both the mathematical function parameters, reported in Table 4, and the input variables, evaluated as the resolution of the AM machine (see Table 6). In order to evaluate the standard deviations of the input variables, shown in Table 6, it was assumed that they were uniformly distributed within their resolution range [40]. The variance-covariance matrix used for the calculation, see Eq. (1), was derived by the software MINITAB®. The computations were performed using the software $M A T L A B \circledR$ and the variance of hardness is finally reported in Eq. (6).

$V A R(\mathrm{HB}) \approx\left[\frac{\partial H B}{\partial \boldsymbol{K}}\right]^{\mathrm{T}} \cdot \operatorname{cov}(\boldsymbol{K}) \cdot\left[\frac{\partial H B}{\partial \boldsymbol{K}}\right]=4.62 H B^{2}$

where $\boldsymbol{K}=\left[P, v, h_{d}, v \cdot v, v \cdot h_{d}, \beta_{0}, \beta_{1}, \beta_{2}, \beta_{3}, \beta_{4}, \beta_{5}\right]^{\mathrm{T}}$.

The probability of occurrence of the defective-output variable HB was obtained under the hypothesis of normal distribution. Specifically, given the optimal value of hardness reported in Table 5, the related variance shown in Eq. (6), and the specification limit, the probabilities of occurrence of defect, $p_{\mathrm{HB}}$, was derived by applying Eq. (2). The specification limit, set to $114 \mathrm{HB}$, was fixed according to technological requirements for the produced parts. The resulting probability is shown in Eq. (7).

$p_{H B}=P(H B \leq L S L)=0.55 \%$

\section{Conclusions}

Although extensive research has been carried out on the optimisation of material properties of components produced by additive manufacturing, relatively little attention has been paid to the quantification of possible defects occurring in the process when it is optimised. Indeed, although the probability of defects occurring is typically small when the process is optimised, this cannot be neglected when planning inspections. So far, published studies have been limited to the identification of possible relationships between process variables and surface properties and their consequent optimisation. The present study aimed to contribute to this growing area of research by presenting a new method to estimate
Table 6 Variability range and standard deviation of input variables, under the assumption of uniform distributions

\begin{tabular}{lll}
\hline Input variable & Variability range & Standard deviation \\
\hline Laser power $(\mathrm{W})$ & $(P \pm 0.05)$ & $\sqrt{0.05^{2} / 3}=2.89 \times 10^{-2}$ \\
Scan speed $(\mathrm{mm} / \mathrm{s})$ & $(v \pm 0.05)$ & $\sqrt{0.05^{2} / 3}=2.89 \times 10^{-2}$ \\
Hatching distance $(\mathrm{mm})$ & $\left(h_{d} \pm 0.005\right)$ & $\sqrt{0.005^{2} / 3}=2.89 \times 10^{-3}$ \\
\hline
\end{tabular}


the probability of occurrence of macro-hardness defect in AlSi10Mg parts produced by SLM process with an EOS M 290 machine, operating under optimal working conditions.

The first step of the proposed methodology aimed to determine the effect of some process variables on the Brinell macro-hardness of SLM parts, through statistically designed experiments. Selected process variables were laser power, scan speed and hatching distance of in-skin, i.e. the core, of the parts. A $3^{3}$ full factorial design was realised in order to evaluate possible non-linear effects of process variables. It was found that scan speed, hatching distance, their interaction, and the quadratic effect of scan speed have the most significant influence on the hardness. The response surface methodology (RSM) provided the mathematical model relating the process variables to the hardness. By optimising this response surface, it was obtained that hardness is maximised when the laser power is $340 \mathrm{~W}$, the scan speed is $1538.4 \mathrm{~mm} / \mathrm{s}$, and the hatching distance is $0.19 \mathrm{~mm}$. Afterwards, the probability of occurrence of hardness defect was estimated by exploiting all sources of uncertainty originating from the mathematical model and the process variables. Considering a lower specification limit of $114 \mathrm{HB}$, the probability of occurrence of hardness defect was $0.55 \%$.

In addition to the optimal configuration of the process variables, the most significant contribution of this study has been to propose a methodology based on design of experiments, response surface methodology and the composition of uncertainties which allows:

- The identification of process variables and interactions which have a significant effect on the hardness;

- The definition of a mathematical model relating process variables and hardness;

- The estimation of the probability of occurrence of hardness defect under optimal working conditions.

By providing a quantitative assessment of hardness defect probability, this study can help researchers and practitioners in their understanding of the SLM process in terms of defect generation. Operatively, the approach herein presented has the great potential of supporting inspection designers in the planning of effective quality inspection strategies during the early phases of inspection planning.

Acknowledgments Open access funding provided by Politecnico di Torino within the CRUI-CARE Agreement. The authors are thankful to Dr. Flaviana Calignano for the support in the definition of samples geometry and in the selection of process variables.

Funding This work has been partially supported by "Ministero dell'Istruzione, dell'Università e della Ricerca" Award "TESUN83486178370409 finanziamento dipartimenti di eccellenza CAP. 1694 TIT. 232 ART. 6" and by the FCA-POLITO-2018 Project "Quality control of surface mechanical properties and topographical features of manufacts by additive manufacturing".
Open Access This article is licensed under a Creative Commons Attribution 4.0 International License, which permits use, sharing, adaptation, distribution and reproduction in any medium or format, as long as you give appropriate credit to the original author(s) and the source, provide a link to the Creative Commons licence, and indicate if changes were made. The images or other third party material in this article are included in the article's Creative Commons licence, unless indicated otherwise in a credit line to the material. If material is not included in the article's Creative Commons licence and your intended use is not permitted by statutory regulation or exceeds the permitted use, you will need to obtain permission directly from the copyright holder. To view a copy of this licence, visit http://creativecommons.org/licenses/by/4.0/.

\section{References}

1. ISO/ASTM 52900:2015(E). (2015). Standard terminology for additive manufacturing technologies-General principles-Terminology. ISO/ASTM International.

2. Grasso, M., \& Colosimo, B. M. (2017). Process defects and in situ monitoring methods in metal powder bed fusion: A review. Measurement Science and Technology, 28, 44005.

3. Calignano, F., Manfredi, D., Ambrosio, E. P., et al. (2013). Influence of process parameters on surface roughness of aluminum parts produced by DMLS. International Journal of Advanced Manufacturing Technology, 67, 2743-2751.

4. Renjith, S. C., Park, K., \& Kremer, G. E. O. (2020). A design framework for additive manufacturing: Integration of additive manufacturing capabilities in the early design process. International Journal of Precision Engineering and Manufacturing, 21, 329-345.

5. Busachi, A., Erkoyuncu, J., Colegrove, P., et al. (2017). A review of additive manufacturing technology and cost estimation techniques for the defence sector. CIRP Journal of Manufacturing Science and Technology, 19, 117-128.

6. Park, J.-H., Goo, B., \& Park, K. (2019). Topology optimization and additive manufacturing of customized sports item considering orthotropic anisotropy. International Journal of Precision Engineering and Manufacturing, 20, 1443-1450.

7. Patterson, A. E., Messimer, S. L., \& Farrington, P. A. (2017). Overhanging features and the SLM/DMLS residual stresses problem: Review and future research need. Technologies, 5, 15.

8. Yao, X., Moon, S. K., Lee, B. Y., \& Bi, G. (2017). Effects of heat treatment on microstructures and tensile properties of IN718/TiC nanocomposite fabricated by selective laser melting. International Journal of Precision Engineering and Manufacturing, 18, 1693-1701.

9. Simchi, A., Petzoldt, F., \& Pohl, H. (2003). On the development of direct metal laser sintering for rapid tooling. Journal of Materials Processing Technology, 141, 319-328.

10. Simchi, A. (2006). Direct laser sintering of metal powders: Mechanism, kinetics and microstructural features. Materials Science and Engineering A, 428, 148-158.

11. Manfredi, D., Calignano, F., Krishnan, M., et al. (2013). From powders to dense metal parts: Characterization of a commercial AlSiMg alloy processed through direct metal laser sintering. Materials (Basel), 6, 856-869.

12. Yan, C., Hao, L., Hussein, A., et al. (2015). Microstructure and mechanical properties of aluminium alloy cellular lattice structures manufactured by direct metal laser sintering. Materials Science and Engineering A, 628, 238-246.

13. Salman, O. O., Brenne, F., Niendorf, T., et al. (2019). Impact of the scanning strategy on the mechanical behavior of $316 \mathrm{~L}$ steel synthesized by selective laser melting. Journal of Manufacturing Processes, 45, 255-261. 
14. Deckers, J., Shahzad, K., Vleugels, J., \& Kruth, J.-P. (2012). Isostatic pressing assisted indirect selective laser sintering of alumina components. Rapid Prototyping Journal, 18, 409-419.

15. Shahzad, K., Deckers, J., Kruth, J.-P., \& Vleugels, J. (2013). Additive manufacturing of alumina parts by indirect selective laser sintering and post processing. Journal of Materials Processing Technology, 213, 1484-1494.

16. Shahzad, K., Deckers, J., Boury, S., et al. (2012). Preparation and indirect selective laser sintering of alumina/PA microspheres. Ceramic International, 38, 1241-1247.

17. Dewidar, M., \& Dalgarno, K. W. (2008). A comparison between direct and indirect laser sintering of metals. Journal of Materials Science and Technology, 24, 227-232.

18. Boschetto, A., \& Bottini, L. (2019). Manufacturability of nonassembly joints fabricated in AlSi $10 \mathrm{Mg}$ by selective laser melting. Journal of Manufacturing Processes, 37, 425-437.

19. Schmidt, M., Merklein, M., Bourell, D., et al. (2017). Laser based additive manufacturing in industry and academia. CIRP Annals, 66, 561-583.

20. Kuo, C., Su, C., \& Chiang, A. (2017). Parametric optimization of density and dimensions in three-dimensional printing of Ti-6Al-4V powders on titanium plates using selective laser melting. International Journal of Precision Engineering and Manufacturing, 18, 1609-1618.

21. Zhu, Y., Zhao, J., Zhang, M., et al. (2020). An Improved density-based design method of additive manufacturing fabricated inhomogeneous cellular-solid structures. International Journal of Precision Engineering and Manufacturing, 21, 103-116.

22. Delgado, J., Ciurana, J., \& Rodríguez, C. A. (2012). Influence of process parameters on part quality and mechanical properties for DMLS and SLM with iron-based materials. International Journal of Advanced Manufacturing Technology, 60, 601-610.

23. Kempen, K., Thijs, L., Van Humbeeck, J., \& Kruth, J.-P. (2012). Mechanical properties of AlSi10Mg produced by selective laser melting. Physics Procedia, 39, 439-446.

24. Cacace, S., \& Semeraro, Q. (2018). About fluence and process parameters on maraging steel processed by selective laser melting: Do they convey the same information? International Journal of Precision Engineering and Manufacturing, 19, 1873-1884.

25. Spierings, A. B., Levy, G., \& Wegener, K. (2014). Designing material properties locally with additive manufacturing technology SLM. In Solid freeform fabrication symposium 2012. ETH-Zürich.

26. Averyanova, M., Cicala, E., Bertrand, P., \& Grevey, D. (2012). Experimental design approach to optimize selective laser melting of martensitic 17-4 PH powder: Part I-Single laser tracks and first layer. Rapid Prototyping Journal, 18, 28-37.

27. Aboutaleb, A. M., Mahtabi, M. J., Tschopp, M. A., \& Bian, L. (2019). Multi-objective accelerated process optimization of mechanical properties in laser-based additive manufacturing: Case study on selective laser melting (SLM) Ti-6Al-4V. Journal of Manufacturing Processes, 38, 432-444.

28. Zhang, S., Rauniyar, S., Shrestha, S., et al. (2019). An experimental study of tensile property variability in selective laser melting. Journal of Manufacturing Processes, 43, 26-35.

29. Montgomery, D. C., Runger, G. C., \& Hubele, N. F. (2010). Engineering statistics (5th ed.). Hoboken: Wiley.

30. Verna, E., Genta, G., Galetto, M., \& Franceschini, F. (2020). Planning offline inspection strategies in low-volume manufacturing processes. Quality Engineering. https://doi.org/10.1080/08982 112.2020.1739309.

31. Galetto, M., Verna, E., Genta, G., \& Franceschini, F. (2020). Uncertainty evaluation in the prediction of defects and costs for quality inspection planning in low-volume productions. The
International Journal of Advanced Manufacturing Technology, 108, 3793-3805. https://doi.org/10.1007/s00170-020-05356-0.

32. See, J. E. (2012). Visual inspection: A review of the literature. Sandia Rep SAND2012-8590, Sandia Natl Lab Albuquerque, New Mex.

33. Savio, E., De Chiffre, L., Carmignato, S., \& Meinertz, J. (2016). Economic benefits of metrology in manufacturing. CIRP Annals, $65,495-498$.

34. Bress, T. (2017). Heuristics for managing trainable binary inspection systems. Quality Engineering, 29, 262-272.

35. Verna, E., Genta, G., Galetto, M., \& Franceschini, F. (2019). Designing offline inspection strategies for selective laser melting additive manufacturing processes. In Proceedings of the XIV Convegno dell'Associazione Italiana Tecnologie Manifatturiere. Associazione Italiana Tecnologie Manifatturiere, Padova, Italy.

36. Franceschini, F., Galetto, M., Genta, G., \& Maisano, D. A. (2018). Selection of quality-inspection procedures for short-run productions. International Journal of Advanced Manufacturing Technology, 99, 2537-2547.

37. Genta, G., Galetto, M., \& Franceschini, F. (2018). Product complexity and design of inspection strategies for assembly manufacturing processes. International Journal of Production Research, 56, 4056-4066.

38. Galetto, M., Verna, E., \& Genta, G. (2018). Robustness analysis of inspection design parameters for assembly of short-run manufacturing processes. In J. Berbegal-Mirabent, F. Marimon, M. Casadesús, \& P. Sampaio (Eds.), Proceedings book of the 3rd international conference on quality engineering and management. International conference on quality engineering and management, Barcelona, Spain (pp 255-274).

39. Montgomery, D. C. (2017). Design and analysis of experiments (9th ed.). New York: Wiley Sons.

40. JCGM 100:2008. (2008). Evaluation of measurement dataGuide to the expression of uncertainty in measurement (GUM). JCGM, Sèvres, France.

41. Devore, J. L. (2011). Probability and statistics for engineering and the sciences. Boston: Cengage Learning.

42. Montgomery, D. C. (2012). Statistical quality control (7th ed.). New York: Wiley.

43. Trevisan, F., Calignano, F., Lorusso, M., et al. (2017). On the selective laser melting (SLM) of the AlSi10Mg alloy: Process, microstructure, and mechanical properties. Materials (Basel), 10, 76.

44. Ghasri-Khouzani, M., Peng, H., Attardo, R., et al. (2019). Comparing microstructure and hardness of direct metal laser sintered AlSi10Mg alloy between different planes. Journal of Manufacturing Processes, 37, 274-280.

45. Maculotti, G., Genta, G., Lorusso, M., \& Galetto, M. (2019). Assessment of heat treatment effect on AlSi10Mg by selective laser melting through indentation testing. Key Engineering Materials, 813, 171-177.

46. Vilaro, T., Abed, S., \& Knapp, W. (2008). Direct manufacturing of technical parts using selective laser melting: Example of automotive application. In Proceedings of the 12th European Forum on Rapid Prototyping, Paris.

47. Wong, M., Tsopanos, S., Sutcliffe, C. J., \& Owen, I. (2007). Selective laser melting of heat transfer devices. Rapid Prototyping Journal, 13, 291-297.

48. Gibson, I., Rosen, D. W., \& Stucker, B. (2010). Additive manufacturing technologies. New York: Springer.

49. Levy, G. N., Schindel, R., Schleiss, P., \& Spierings, A. (2006). Total quality management (TQM) model for rapid manufacturing. In Rapid manufacturing conference, Loughborough.

50. Read, N., Wang, W., Essa, K., \& Attallah, M. M. (2015). Selective laser melting of AlSi10Mg alloy: Process optimisation and 
mechanical properties development. Materials and Design, 65, 417-424.

51. Schmid, M., \& Levy, G. (2012). Quality management and estimation of quality costs for additive manufacturing with SLS. In Fraunhofer direct digital manufacturing conference, Berlin.

52. Thijs, L., Kempen, K., Kruth, J. P., \& Van Humbeeck, J. (2013). Fine-structured aluminium products with controllable texture by selective laser melting of pre-alloyed AlSi10Mg powder. Acta Materialia, 61, 1809-1819.

53. Pakkanen, J., Calignano, F., Trevisan, F., et al. (2016). Study of internal channel surface roughnesses manufactured by selective laser melting in aluminum and titanium alloys. Metallurgical and Materials Transactions A: Physical Metallurgy and Materials Science, 47, 3837-3844.

54. Kwon, D., Park, E., Ha, S., \& Kim, N. (2017). Effect of humidity changes on dimensional stability of 3D printed parts by selective laser sintering. International Journal of Precision Engineering and Manufacturing, 18, 1275-1280.

55. Gusarov, A. V., Yadroitsev, I., Bertrand, P., \& Smurov, I. (2007). Heat transfer modelling and stability analysis of selective laser melting. Applied Surface Science, 254, 975-979.

56. Gusarov, A. V., Yadroitsev, I., Bertrand, P., \& Smurov, I. (2009). Model of radiation and heat transfer in laser-powder interaction zone at selective laser melting. Journal of Heat Transfer, 131, 072101.

57. Masoomi, M., Gao, X., \& Thompson, S. M., et al. (2015). Modeliing, simulation and experimental validation of heat transfer during selective laser melting. In Proceedings of the ASME 2015 international mechanical engineering congress and exposition IMECE2015, Houston, Texas.

58. Krishnan, M., Atzeni, E., Canali, R., et al. (2014). On the effect of process parameters on properties of $\mathrm{AlSi} 10 \mathrm{Mg}$ parts produced by DMLS. Rapid Prototyping Journal, 20, 449-458.

59. Manfredi, D., Calignano, F., Krishnan, M., et al. (2014). Additive manufacturing of $\mathrm{Al}$ alloys and aluminium matric composites (AMCs). In W. A. Monteiro (Ed.), Light metal alloys applications (p. 64). London: IntechOpen.

60. Salmi, A., Atzeni, E., Iuliano, L., \& Galati, M. (2017). Experimental analysis of residual stresses on AlSi10Mg parts produced by means of selective laser melting (SLM). Procedia CIRP, 62, 458-463.

61. Tian, Y., Tomus, D., Rometsch, P., \& Wu, X. (2017). Influences of processing parameters on surface roughness of Hastelloy $\mathrm{X}$ produced by selective laser melting. Additive Manufacturing, 13, 103-112.

62. Yan, C., Hao, L., Hussein, A., et al. (2014). Evaluation of lightweight AlSi10Mg periodic cellular lattice structures fabricated via direct metal laser sintering. Journal of Materials Processing Technology, 214, 856-864.

63. Kempen, K., Thijs, L., Van Humbeeck, J., \& Kruth, J.-P. (2015). Processing AlSi10Mg by selective laser melting: Parameter optimisation and material characterisation. Materials Science and Technology, 31, 917-923.

64. Adam, G. A. O., \& Zimmer, D. (2014). Design for additive manufacturing-Element transitions and aggregated structures. CIRP Journal of Manufacturing Science and Technology, 7, 20-28.

65. Cain, V., Thijs, L., Van Humbeeck, J., et al. (2015). Crack propagation and fracture toughness of Ti6Al4V alloy produced by selective laser melting. Additive Manufacturing, 5, 68-76.

66. Bo, S., Shujuan, D., Qi, L., et al. (2014). Vacuum heat treatment of iron parts produced by selective laser melting: Microstructure, residual stress and tensile behavior. Materials and Design, 54, 727-733.

67. Childs, T. H. G., Hauser, G., \& Badrossamay, M. (2005). Selective laser sintering (melting) of stainless and tool steel powders: Experiments and modelling. Proceedings of the Institution of Mechanical Engineers, Part B: Journal of Engineering Manufacture, 219, 339-357.

68. Li, Y., \& Gu, D. (2014). Parametric analysis of thermal behavior during selective laser melting additive manufacturing of aluminum alloy powder. Materials and Design, 63, 856-867.

69. Song, B., Zhao, X., Li, S., et al. (2015). Differences in microstructure and properties between selective laser melting and traditional manufacturing for fabrication of metal parts: A review. Frontiers of Mechanical Engineering, 10, 111-125.

70. Lam, L. P., Zhang, D. Q., Liu, Z. H., \& Chua, C. K. (2015). Phase analysis and microstructure characterisation of AlSi10Mg parts produced by selective laser melting. Virtual and Physical Prototyping, 10, 207-215.

71. Li, X. P., O’Donnell, K. M., \& Sercombe, T. B. (2016). Selective laser melting of Al-12Si alloy: Enhanced densification via powder drying. Additive Manufacturing, 10, 10-14.

72. Mason, R. L., Gunst, R. F., \& Hess, J. L. (2003). Statistical design and analysis of experiments: With applications to engineering and science (2nd ed.). New York: Wiley.

73. ISO 6506-1:2014. (2014). Metallic materials-Brinell hardness Test Part 1: Test method. International Organization for Standardization, Genève.

Publisher's Note Springer Nature remains neutral with regard to jurisdictional claims in published maps and institutional affiliations.

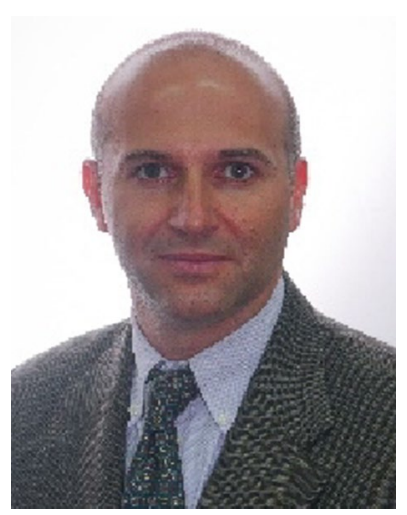

Maurizio Galetto received the Master of Science Degree in "Physics" from University of Turin, Italy, in 1995 and the $\mathrm{PhD}$ Degree in "Metrology: Measuring Science and Technique" from Politecnico di Torino, Italy, in 2000 . He is currently Had of Department and Full Professor at the Department of Management and Production Engineering (DIGEP) of the Politecnico di Torino, where he teaches "Quality Engineering" and "Experimental Statistics and Mechanical Measurement". He is Associate Member of CIRP (The International Academy for Production Engineering) and Fellow of A.I.Te.M. (Associazione Italiana di Tecnologia Meccanica) and E.N.B.I.S. (European Network for Business and Industrial Statistics). He is Member of the Editorial Board of the scientific international journal Nanomanufacturing and Metrology and collaborates as referee for many international journals in the field of Industrial Engineering. He is author and coauthor of 4 books and more than 100 published papers in scientific journals and international conference proceedings. His current research interests are in the areas of Quality Engineering, Statistical Process Control, Industrial Metrology and Production Systems. At present, he collaborates in some important research projects for public and private organizations. 


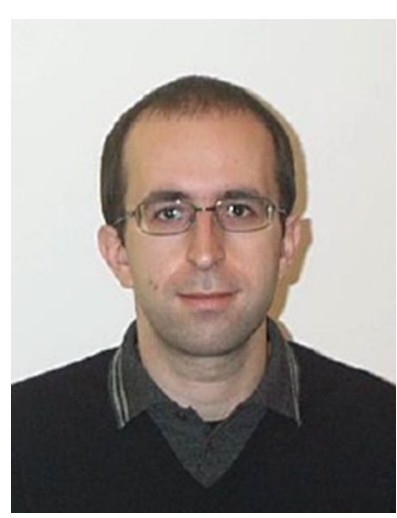

Gianfranco Genta received the Master of Science Degree in Mathematical Engineering from Politecnico di Torino, Italy, in 2005 and the Ph.D. Degree in "Metrology: Measuring Science and Technique" from Politecnico di Torino in 2010 . He is currently Fixed-Term Researcher at the Department of Management and Production Engineering (DIGEP) of the Politecnico di Torino, where he has been teaching "Experimental Statistics and Mechanical Measurement" since 2012. He is Research Affiliate of CIRP (The International Academy for Production Engineering) and Fellow of A.I.Te.M. (Associazione Italiana di Tecnologia Meccanica). He is author and coauthor of 3 books and more than 40 publications on national/international journals and conference proceedings. His current research focuses on Industrial Metrology, Quality Engineering and Experimental Data Analysis.

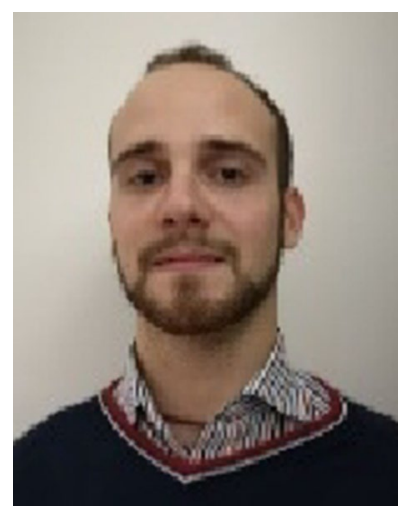

Giacomo Maculotti received the Master of Science Degree in Automotive Engineering in 2017 from Politecnico di Torino, Italy. $\mathrm{He}$ is currently Ph.D. student at Politecnico di Torino - Dept. of Management and Production Engineering (DIGEP). His current research interests are Industrial Metrology, Technological Surfaces Characterization, and Quality Engineering.

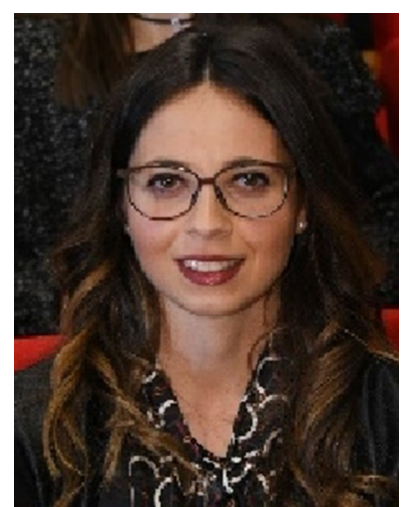

Elisa Verna received the Master of Science Degree in "Engineering and Management" from Politecnico di Torino, Italy, in 2016. She is currently Ph.D. student in "Management, Production and Design" at the Department of Management and Production Engineering (DIGEP) of Politecnico di Torino. Her current research interests are in the areas of Quality Engineering, Statistical Process Control and Innovative Production Systems. 